\section{THE AURORA 1}

\section{II.}

WE next come to the I I-year period. On this the following pertinent remarks are made :-

"It will be perfectly clear that it is chiefly observations from the Temperate Zone which have constituted the material for demonstrating the eleven-year period But as regards the Polar regions, it has been assumed that either the Aurora Borealis also follows the same laws in these parts, or that it appears with the same force and same manner all the year round. Neither of these alternatives seem, however, to be right, as a series of observations prosecuted with great care during fifteen years at Godthaab, in Greenland, have brought me to the somewhat remarkable conclusion that, as regards the varying frequency of the Aurora Borealis at Godthaab, the law seems to be the reverse of that ruling in southern latitudes.

"These researches, which were effected by Mr. S. Kleinschmidt, extend over a period from August 1865 to May 1880 . The number of days with auroræ in the year, reckoned from August to May, were :-

$\begin{array}{ccccccccc}\text { ×865-66 } & 66-67 & 67-68 & 68-69 & 69-70 & 70-75 & 71-72 & 72-73 & 73-74 \\ 97 & \text { II } 2 & 65 & 84 & 45 & 61 & 32 & 47 & 73 \\ & 1874-75 & 75-76 & 76-77 & 77-78 & 78-79 & 79-80 & \\ & 97 & 97 & 104 & 69 & 100 & 75 & \end{array}$

"This series cannot, however, be accepted as giving the exact view of the relation between the varying frequency of the auroræ, because the state of the clouds would exercise-a great influence on the visibility of auroræ. If thus the clouds vary greatly from one year to another, this circumstance would greatly reduce the number of auroræ. A closer study of the nebulous conditions at Godthaab, compared with the frequency of the auroræ, has caused me to consider that the number of auroræe decrease in proportion as the clouds increase in quantity. The above-recorded auroral totals must, therefore, be reduced to the same cloud unit i.e. it must be calculated how great the number would have been had the nebuiosity been the same every year. By this we obtain the values given under $N$. Under $S$. is given the relation between the sun-spots in the same year (July to June).

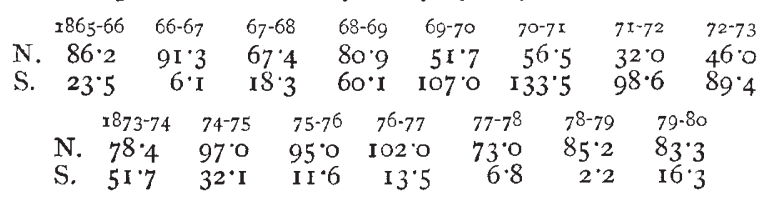

"If the two series be compared it will be found that the law of relation between the frequency of sun-spots and aurore is reversed. This fact will be still more apparent from Fig. 4, where both series of auroræ and sun-spots are shown graphically.

"The few series of observations which we possess from other Polar regions, and which I have been able to analyse, indicate, though incomplete, similar conditions.

"As the greater part of the Godthaab observations were made in the morning, I have not only used the aturoral days for my researches-reckoned from noon to noonbut also examined evening and morning auroræ separately. The evening and morning auroræ lead, as regards the eleven-year period, to the same conclusion as the auroral days, i.e. that the Auror a Borealis is scarcest under sunspot maxima.". .

"If we consider the relation between zenith and southern auroræ in the various years of the Godthaab researches, we obtain the interesting result that the percentages of zenith aurorre in the main follow those of the auroral frequencies, i.e., that at the periods of maxima at

I "Under the Rays of the Aurora Borealis." By S. Tromholt. Edited by Carl Siewers. (London: Sampson Low and Co., I885.) Continued from p. 276 .
Godthaab, the aurore which fall in the zenith of this place or further north, are not only absolutely, but also relatively, more frequent than at the periods of minima. And what deduction may be drawn from this? The deduction that the auroral zone in the course of the eleven-year period makes a movement too, of such a nature that it lies further north when the sun-spots are in their minimum than in their maximum period.

"If this result be compared with what I have already propounded as to the eleven-year period in the Arctic regions, the interesting explanation will be obtained of the phenomenon, that this period in Greenland and similarly-situated places shows a reverse course to that in more southern regions. The auroral maximum, occurring in the temperate regions simultaneously with the sun-spot maximum, is due to the auroral zone being then in its southernmost position, which again causes an auroral minimum in the polar regions, and, in a reverse manner, the auroral zone has its northernmost position when the sun-spots are in the minimum, which then causes an auroral minimum in the temperate regions and a maximum one in those around tile Pole."

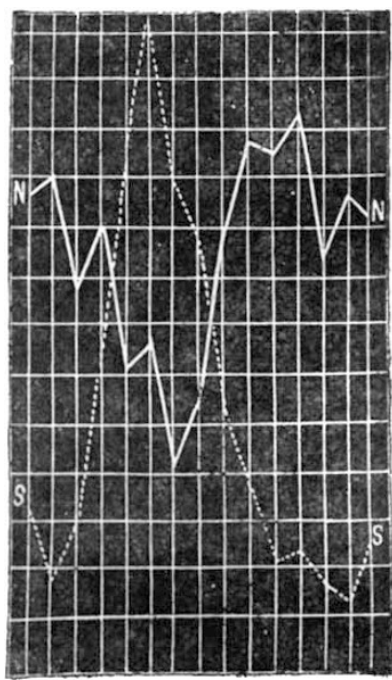

FIG. 4-Comparison of auroral frequencies at Godthaab with sun-spots. $\mathrm{N}=$ Northern light frequencies; $\mathrm{S}=$ Spot frequencies.

These very beautiful results will show that there can be very little doubt about the movement of the auroral zone as a whole.

The next point on which much light is thrown by $\mathrm{Mr}$. Tromholt's work is that the various appearances are in the main due to movements bringing auroral striæ in different relation to the spectator:-

"In one respect in particular my sojourn at Koutokæino was very instructive-viz. with regard to the understanding of the true shape and position, and the changes to which the aurora is apparently subjected when altering its elevation above the horizon. Partly through the frequency of the aurora, and partly by its appearance now in the north, now in the south, and now in the zenith, there were excellent opportunities of studying the modifications which the form suffered as it changed its position in relation to the observer.

"From this I came to the conclusion that the great many different forms referred to might certainly be reduced to a few fundamental ones. In most instances the aurora forms belts or zones, which stretch across the earth in the direction of the magnetic east-west, which zones are formed by a conglomeration of thin sheets of luminous matter ranged one behind the other, their direction being 
parallel with the inclination needle. The luminous matter in these sheets is either even, diffuse, or divided into streamers.

"Everything now depends on the position of the observer in relation to such a zone in order that it may appear in one form or the other. If he be very far from the aurora he will see an arc, diffuse or radiating, according to the nature of the luminous matter. If he approaches he will most probably see several distinct arcs, the phenomenon gathering more force and the colours more life; and when still nearer, the aurora will appear as a band, and, if the luminous matter be radiating and passes the magnetic zenith of the observer, he will behold the auroral corona."

He thus holds that a "band" is a near arc occupy. ing a higher position in the sky :-

"The auroral band is oftenest seen in those parts of the globe which are considered to be the true home of the Aurora Borealis, but seldom, or hardly ever, in southern latitudes. What is chiefly characteristic of the band in opposition to the arc, although no sharp line of distinction can be drawn here either, is its great height above the horizon, but at what elevation it ceases to be band and becomes arc is naturally an arbitrary determination. The band, as well as the arc, may consist of equi-luminous matter, of streamers, and of so-called luminous clouds, and it is, to a higher degree than is the case with the arc, subject to the most violent changes of position, form, and motion. Particularly when the band consists of streamers it displays the richest variations and greatest beauty, the folds of the streaming drapery, the prismatic play of colour, and the light-waves, which with marvellous rapidity course through the graceful undulating rays, forming a spectacle of light, colour, and form which

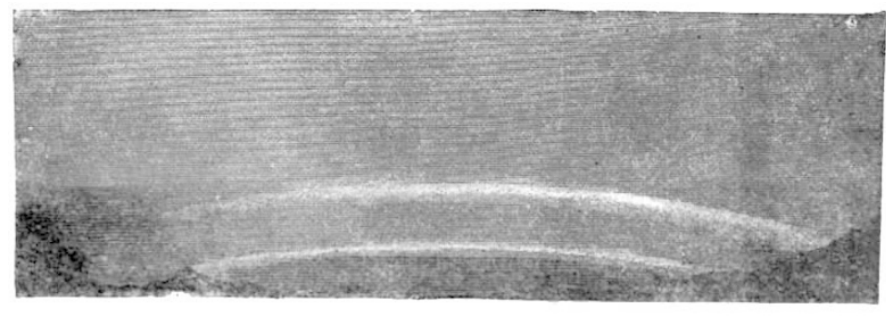

A, at 7 h. $20 \mathrm{~m}$.

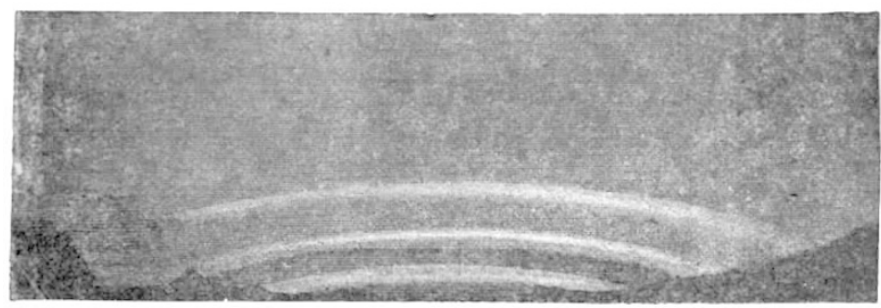

B, at 7 h. $33 m$.

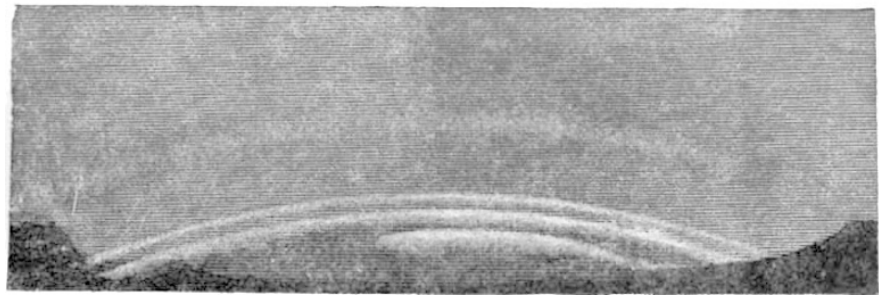

C, at 8 h. rom

FIG. 5.-Phases of an auroral arc, December I, I878.

makes this variety of the Aurora Borealis the most charming of all.

"The perspective fundamental form of the arc, and also the band, may, in my opinion, be explained by the aurora forming one or several rings, or fragments of such, which, with the magnetic pole as centre, or, more correctly, with a point in the magnetic axis of the earth-viz. the straight line between the two magnetic poles-lie at a certain height above the earth's surface. On account of the great circumference of the earth, in proportion to the height of the aurora, only a small portion of such a ring would be visible at one time, and each observer only see his own portion, the situation of which in relation to his horizon and the zenith will depend on his position in relation to the auroral ring."

The auroral streamers are closely associated both with arcs and bands, an arc or band composed of streamers often forming the basis for a colonnade of streamers.

Before we proceed to the consideration of the corona, the following extracts concerning streamers and their apparent motions will be read with interest :-

"The streamers embrace a number of varieties, which have only one peculiarity in common-viz, that the direction is very nearly vertical, and that the length is always greater than the width. The length differs greatly, from $2^{\circ}$ and $3^{\circ}$ to $30^{\circ}$ and $40^{\circ}$ or more. The width is very difficult to estimate, on account of the constant motion; a single streamer thus may form only a slender thread of light, while others may have a width of from $I O^{\prime}$ to $I^{\circ}$, or more. Short streamers form often, as I have mentioned above, bands or arcs. The long streamers gather generally in bunches, which may either remain isolated, or 
particularly when the aurora has previously formed an arc, stand parallel, in such a manner that the lower, intensest, ends nearly follow the track of the former arc. Bunches of streamers, standing high in the sky, are often fan-shaped, the broadest part pointing downwards. The intensest streamers have very clearly defined edges, but from these there are all sorts of variations down to the streak of light hardly visible. At the side of, and between very intense and defined streamers, the sky seems, by the contrast, unusually dark, and this may, perhaps, explain the black streamers which some observers claim to have seen.

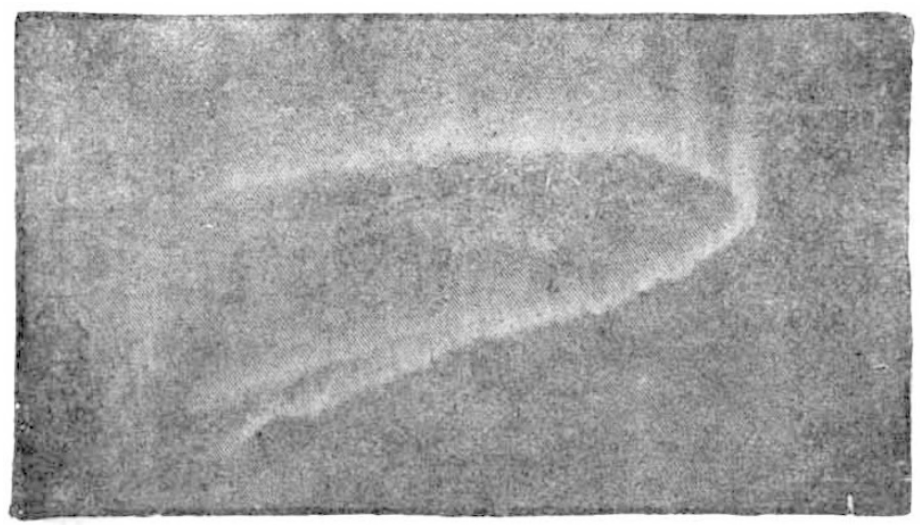

FIG; 6.-Aurora (Koutokaino).

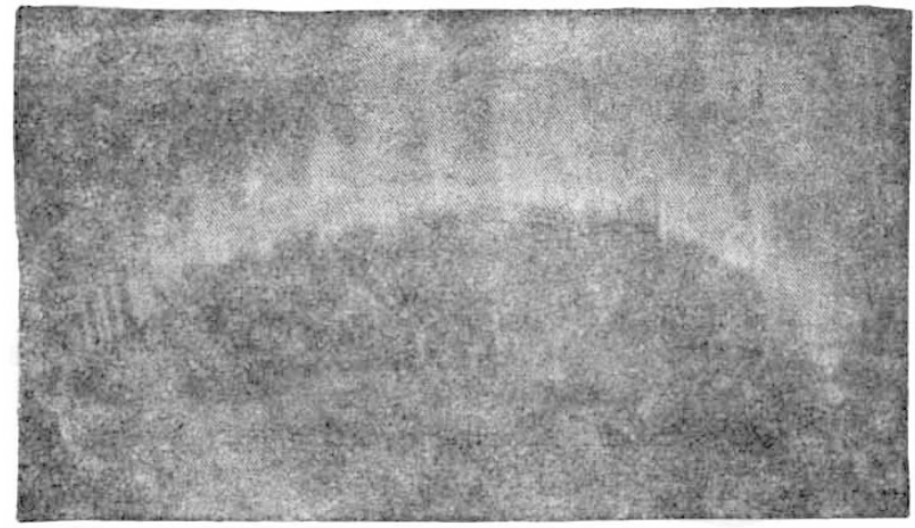

Fifi, 7.-Streamers (Koutokaino).

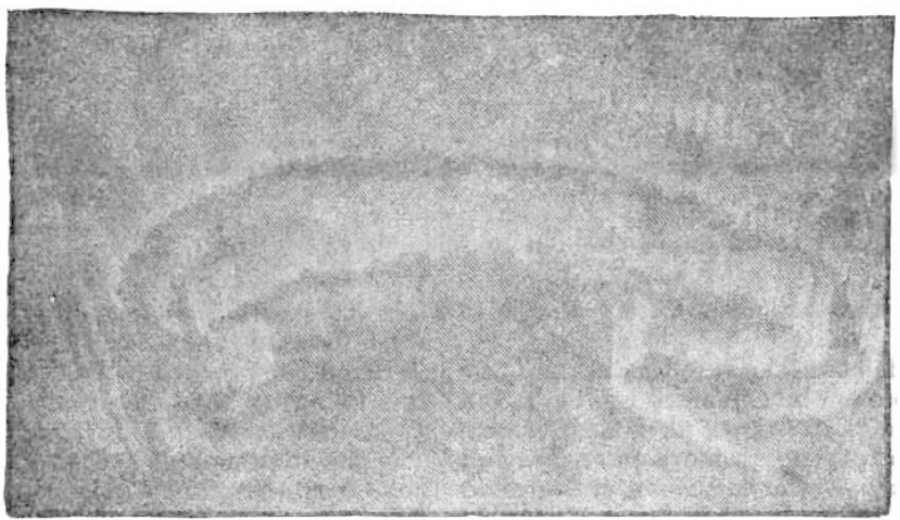

Fig. 8.-Bands and streamers (Koutokaino).

"The points of the streamers are usually faint and with no sharp line of demarcation. The stars shine through the streamers as through all other forms of the aurora, and it may, indeed, be a matter of doubt whether the strength of light of the aurora is ever great enough to outshine a bright star." ...
"The motion of the streamers is twofold. First, longitudinally, as they strike upwards or downwards; and secondly, laterally, as they travel parallel either to the left or right. Sometimes this motion is slow, sometimes very quick, and particularly in the latter case the observer obtains the impression that the colonnade of streamers 
is furrowed transversely by waves of energy following in rapid succession, under the influence of which the streamers momentarily flare up. If this be the case, or the streamers really move, it is impossible to tell.

"The longitudinal course of the streamers is not apparently only, but in reality, very nearly vertical, as several facts prove that they point in the same direction as the magnetic inclination needle."... "In regions near the magnetic pole, where the magnetic inclination is greater, the streamers stand more perpendicularly than in more southern latitudes, where they form a smaller angle with the surface of the earth.

"Some students, as, for instance, Baron Nordenskjöld, have advanced the theory that the streamers do not occupy this position, but lie more parallel with the earth; and, indeed, when observing an apparently perpendicular streamer in the north, it may in reality form any angle with the horizon, and still seem to the eye to stand perpendicular. But from various circumstances it is clear that the direction of the streamers is, as I have stated above-viz. parallel with the inclination needle. This is, in fact, demonstrated not only by the streamers high in the sky, which form the upper part of the corona, but also by those which, under intense aurorae, stand either in the east or west, and which are then seen 'from the side,' so to speak, i.e. they stand very nearly perpendicularly, as indicated to all appearances by the streamers seen to the north 'in front."

The auroral corona, the grandest sight of all, is found at the instant a band or broken band forming a colonnade
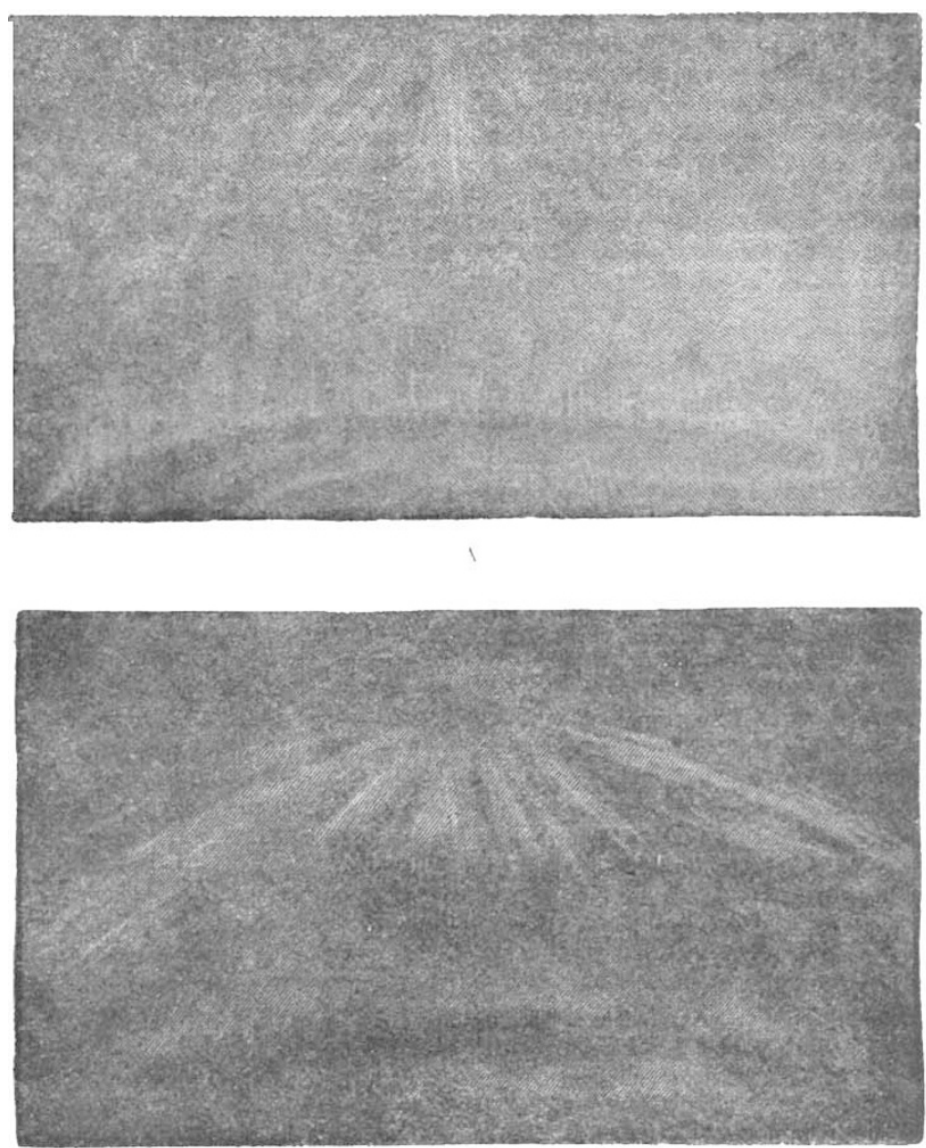

B

FIG. 9. - Coronas (Koutokæino).

of streamers reaches the magnetic zenith in its progress from the north :-

"Quick as lightning streamers break forth at the same moment on the southern side of the magnetic zenith, and as the aurora travels further and further southwards, the corona becomes more and more complete. In northern regions, where the aurora frequently appears high in the sky, in a northerly or southerly direction, there is often an opportunity of seeing this form of the phenomenon, when a band of streamers passes the magnetic zenith in its course north or southwards. It is, however, not always that the aurora's passing of the zenith has the effect of producing the corona; it is seldom the case when a band constituted of diffuse luminous matter passes this point. It is, in fact, the streamers which create the corona." ...
"If it be burne in mind that the course of the auroral streamers is identical with that of the magnetic inclination needle, it is easy to perceive the origin of the ordinary radiating aurora as well as the corona." ...

"This form of the Aurora Borealis, which generally indicates, at all events in southern latitudes, the culmination of the aurora as regards splendour, colour, and development, is produced by the streamers shooting from every part of the sky towards a common point-viz. the magnetic zenith. With this point as centre they seem to radiate in every direction; some are very long, others short, while some form rays or bands one above the other. The heaven thereby assumes the appearance of a huge cupola, or tent of fire. In reality the streamers are all parallel; their appearance of radiating in all directions from a central point with various angles being due to 
perspective causes-viz. by the points of the streamers being further distant than the bases. It is the same perspective peculiarity which causes the lamps in a street or the trees in an avenue to appear to meet in the distance.

"The centre of the corona is sometimes dark-that is to say, the sky is seen between the streamers, at other times the central part is filled with luminous matter.

"It is not only the streamers which contribute to form the corona ; on the contrary, all the forms of the aurora lend their beauty to produce this magnificent display. If to this is added that the Aurora Borealis in such moments develops its greatest strength, richest colour, and most intense light, it will be understood that the corona is that form of the phenomenon which possesses the greatest magnificence and most striking beauty."

With regard to the height of the aurora, a preliminary examination of the observations made in the plane Koutokxino-Bossekop gives from 50 to 100 miles, an average of I 8 measurements giving $70^{\circ} 2$ miles or $\mathrm{I}_{3} 3$ kilometres.

From this long article on auroræ, the reader must not think that our author is exclusively occupied with them. His two volumes are admirable examples of what books of travel should be, and it falls to the lot of few travellers to have such an interesting region to explore, or to have such an important piece of scientific work to accomplish.

\section{THE BRITISH ASSOCIATION}

$\mathrm{O}^{\mathrm{L}}$

$\mathrm{U}$ readers are aware that at the approaching meting of the British Association it has been arranged to have discussions in Section $\mathrm{A}$ on kinetıc theories of gases and on standards of white light. Prof. Crum Brown has consented to open the discussion on the kinetic theories, and has drawn up the following short abstract of points to which he proposes to allude. It would be convenient if persons desiring to take part in the discussion would forward their names, with, if possible, a short abstract, to the recorder, Prof. W. M. Hicks, Firth College, Sheffield.

\section{Diffuculties connected with the Dynamical Theory of Gases. Prof. Crum Brown.}

The Dynamical Theory of Gases appears at first sight to furnish a very complete explanation of all the properties of gases, both physical and chemical. When, however, we come to details, difficulties and apparent contradictions make their appearance. These difficulties have been pointed out from time to time, and some attempts have been made to show that they are not really fatal to the theory as usually stated; but it may be useful that some of them should be brought at this time before the section and regularly discussed.

I shall here merely mention some of these difficulties, as the explanations which have been given of them will be better supplied by others in the discussion.

I. The diffculties connected with the doctrine, that energy communicated from ruthout to a gas is equally shared among the whole of the degrees of freedom of the molecules. This leads to a relation between the numbers of degrees of freedom and the ratio of the specific heat at constant pressure to that at constant volume. This ratio is for mercury gas almost exactly 5:3, from which it would appear that the molecules of mercury gas have not morc than three degrees of freedom-in other words, that the whole energy of mercury gas is kinetic energy of translation of the molecules. But even if we assume that the molecules of mercury are spheres, perfectly smooth and perfectly rigid, the fact that mercury vapour has a spectrum points to some form of energy of a vibratory kind. Again, the gases, the molecules of which are supposed to consist of two atoms, have the ratio of the specific heats nearly equal to $7: 5$ (it seems always to be a little greater than this, which increases the difficulty). This points to five degrees of freedom of the molecule, which would be consistent with the hypothesis that these molecules consist of two smooth, undeformable spheres at a constant distance from each other, the five degrees of freedom being three of translation and two of rotation about two axes, any two at right angles to each other and at right angles to the axis of the molecule, that is, the line joining the centres of the two atoms. But here also we have spectra, and in addition the phenomena of dissociation lead to a belief that the firmness of the union of the two atoms diminishes as temperature rises, and it is difficult to reconcile this with a constant distance of the two atoms from one another in the molecule. Any variation in this distance would be a new degree of freedom in addition to the five allowed by the theory.

All attempts to reconcile chemical action and chemical equilibrium with dynamical conceptions seem to require the assumption of vibrations of the atoms in the molecule, under the influence of forces depending on the distances of the atoms from each other, and perhaps in addition to these, vibrations of the atoms as parts of the' molecule, vibrations of the atoms themselves. In molecules, even of a comparatively simple kind, such considerations imply many degrees of freedom, certainly far more than the dynamical theory of gases as usually understood will admit.

2. Difficulties connected with the doctrine that energy of each kind is distributed among the molecules according to some form of the law of probability.

This implies that in a gas at any temperature there are molecules in the condition as to energy which is the average condition of the gas at any other temperature. That, for instance, at the ordinary atmospheric temperature there are molecules in the condition which is the average condition at a red heat.

This scems inconsistent with what is usually regarded as true, viz., that there are limiting conditions of temperature and pressures, on the one side of which certain chemical changes occur, while they do not occur at all on the other side. Thus at ordinary atmospheric temperatures and pressures, hydrogen and oxygen show no tendency to combine. At a red heat they combine almost completely. At ordinary temperatures phosphorus combines slowly with oxygen if the pressure of the oxygen is below a certain limit (dependent on the temperature), but apparently not at all if the pressure of the oxygen is above that limit. Many other cases might be mentioned, but these may suffice as instances. It is difficult to understand the existence of such definite sharp limits, if the energy is distributed among the molecules according to any asymptolic law. In such a case the rate of chemical action might be expected to diminish, but not to become zero.

I have brought forward these instances of apparent contradiction between the conclusions of the dynamical theory as usually stated, and observed facts in the hope that they may be cleared up. This may conceivably be done in two ways-either by showing that the facts have not been accurately observed, or that the conclusions have not been legitimately drawn from the theory.

\section{NOTES}

THE Iron and Steel Institute holds its summer meeting in Glasgow on September $\mathbf{I}-5$. The programme includes excursions down the Clyde and a visit to the Forth Bridge Works. The following is the list of papers down for reading:- On the iron trade of Scotland, by Mr. F. J. Rowan, Glasgow ; on the rise and progress of the Scotch steel trade, by Mr. James Riley, Glasgow, Member of Council; on the present position and prospects of processes for the recovery of tar and ammonia from blast furnaces, by Mr. Wm. Jones, Langloan Ironworks, N.B. ; on the structural features and working of the South Chicago blast furnaces, by Mr, F. W. Gordon, Philadelphia, and Mr. 